\title{
DOCUMENTATION FOR EMERGENCY STABILIZATION AND THE INTEGRATED CONSERVATION PLANNING OF EARTHEN ARCHITECTURE SETTLEMENTS: THE KASBAH OF TAOURIRT (OUARZAZATE, MOROCCO)
}

\author{
Z.Ekim ${ }^{\text {a, M.Santana Quintero }}{ }^{\text {a }}$, K.Percy ${ }^{\mathrm{a}}$, S.Ward ${ }^{\mathrm{a}}$, S.Fai ${ }^{\mathrm{a}}$, J. Gregg ${ }^{\mathrm{a}}$, C.Ouimet $^{\mathrm{a}}$, C.Cancino ${ }^{\mathrm{b}}$, M.Boussalh $^{\mathrm{c}}$. \\ ${ }^{a}$ Carleton Immersive Media Studio, Carleton University, 1125 Colonel by drive, Ottawa, On, K1S 5B6 Canada \\ ekimzeynep@gmail.com - Mario_santana@carleton.ca - kpercy@gmail.com - sarah_1_ward22@hotmail.com - \\ sfai@cims.carleton.ca - John.Gregg@tpsgc-pwgsc.gc.ca - Christian_ouimet@carleton.ca \\ ${ }^{\mathrm{b}}$ Getty Conservation Institute, 1200 Getty Drive, Suite 700, Los Angeles, CA 90049-1684, USA - ccancino@getty.edu \\ ${ }^{\mathrm{c}}$ Center for Conservation and Rehabilitation of the architectural Heritage of the Atlas and sub-Atlas zones (CERKAS), Kasbah \\ Taourirt, BP 253 Ouarzazate, Morocco - mohamedboussalh@yahoo.fr
}

\section{CIPA Heritage Documentation} KEY WORDS: 3D imaging, Recording, Photogrammetry, EDM, Computer-Aided Drawing, Conservation, Earthen Architecture,
Documentation.

\begin{abstract}
:
Heritage recording serves as a basis for methodologies regarding diagnosis, treatment and preservation of historic places and contributes to make posterity records of our built cultural heritage. This work is not a stand-alone practice, but a part of the overall conservation of cultural heritage. Recording of heritage places should be directly related to the needs, skills and the technology that are available to the end users that are responsible for the management and care of these sites. They should be selected in a way that the future protectors of these sites can also access and use the data that is collected. This contribution explains an innovative heritage recording approach applied by Carleton Immersive Media Studio (CIMS) in the documentation of an earthen complex, the Kasbah of Taourirt in Ouarzazate, Morocco as part of the Earthen Architecture Initiative of the Getty Conservation Institute (GCI). The selected recording techniques used were carried out according to the requirements of the Moroccan team (CERKAS) in charge of the study and protection of the chosen site documented.
\end{abstract}

\section{INTRODUCTION}

\subsection{Context}

Kasbah of Taourirt is one of several major earthen complexes along the former caravan route between the Sahara dessert and the city of Marrakech in Southern Morocco. This massive earthen complex of two hectares is located in the city of Ouarzazate, situated about an hour away from Marrakech. It was built in the 16th century by the Glaoui family that dominated the Southern Atlas Region. During its peak of importance in the mid $19^{\text {th }}$ century, the Kasbah of Taourirt held a strategically important location in order to control the Saharan Caravan Route to West Africa. After the French domination in the region, when the Glaoui lost their dominance over the region in 1930 s, settlers and squatters started occupying the site and used it for housing purposes and artisan shops until 2010. Although part of the site of Taourirt is restored and functioning as a museum, the site is various degrees of ruins.

\subsection{Project and Objectives}

The documentation of this historic site was undertaken by CIMS in accordance with the GCI as part of their Earthen Architecture Initiative, which aims to develop a rehabilitation approach of earthen architecture settlements using the Kasbah of Taourirt as a case study.

The recording was primarily captured by survey using a Total Station and photogrammetry techniques. These methods were chosen by taking the complexity of the structure, portability of equipment, the given time frame to document the structure and the extent of the spatial geography into consideration. In addition to the fact that these technologies were easy to transfer to the local team (CERKAS) in Morocco and that they are cost effective.

The recording team consisted of six heritage recorders which carried out 21 days of fieldwork, primarily using direct and indirect surveying techniques involving total stations and photogrammetry. The data acquired from the survey and photogrammetric models was used to create a site atlas, consisting of floor plans, elevations and sections.

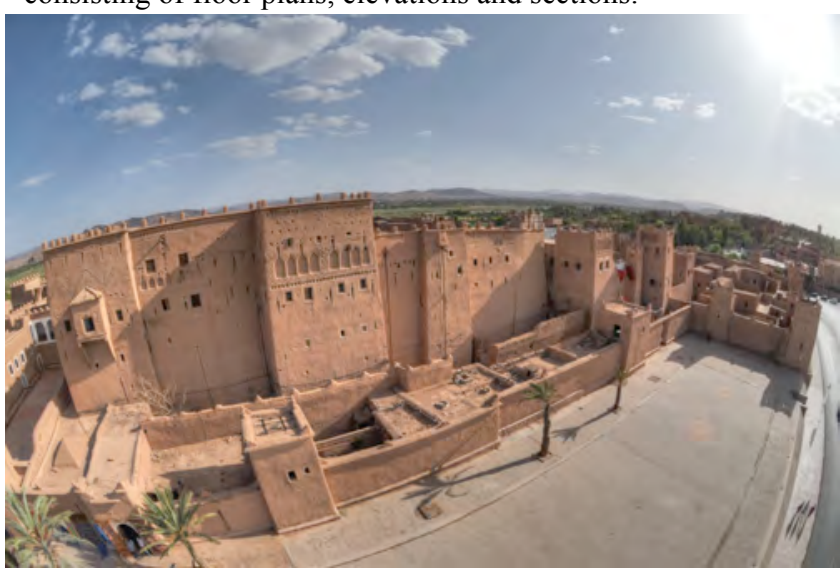

Figure 1: Kasbah of Taourirt aerial view.

\section{THE DOCUMENTATION PROCESS}

\subsection{Selection of Documentation Techniques}

The selection of the documentation techniques for the Morocco stream of the Earthen Architecture initiative was based upon the availability of technology, the ability of each method to be imparted to the local CERKAS team, and the efficiency of each method. It was decided that a Total Station EDM was preferable 
over other techniques such as laser scanning due to the mobility of the equipment and its availability for the CERKAS team in Ouarzazate. The use of a Total Station proved ultimately to be a more efficient technique to learn within the short time frame of the field project. Photogrammetry was implemented during the field project as a means of improving efficiency after truly understanding the scope of work and the size of the rooms and exterior spaces to be documented. Once a complete traverse system/network was produced, it was feasible to use photogrammetry to complement the survey (which was captured using a Total Station) information and to increase the productivity of the overall documentation. Photogrammetry also proved useful in creating multiple drawing types, such as $3 \mathrm{~d}$ models and orthographic photos. Hand measurements were implemented in instances where the Total Station captured the majority of the data required, yet additional heights and details were taken in order to complete the space. This technique was employed mainly where there was a requirement to produce a section in a room documented with the Total Station.

\subsection{Recording the Geometric Configuration of the Kasbah}

The preparation of the digital recording of the Kasbah of Taourirt's historic fabric was carried out with the help of several surveying instruments, among them, Electronic Distance Measurement (EDM) equipped Total Stations connected to tablet PCs running AutoCAD were utilized. The measurements collected by the EDMs were translated to AutoCAD commands using an off-the-shelf available software called TheoLT.

Furthermore, the EDM Total Stations were used to support the photogrammetric record and the survey of the individual spaces (plans, elevations and sections), by calculating a survey network of the interior and exterior perimeter of the Kasbah.

The network was closed, verified and adjusted using traversing calculations. With the traverse in place, the network branched out into smaller rooms from the main survey network. Where possible, the network legs were verified by measuring a second adjusted network point to ensure that the survey was within the precision tolerance of the project.

Because multiple teams were working with hundreds of surveyed targets distributed throughout the Kasbah, a core list of targets names and their coordinates was compiled every morning and uploaded into each team's tablet. This ensured that the most current available measured points were available to all teams if and when needed.

By using a minimum of three targets per room, the rooms were attached together via clusters of smaller surveys which were grouped and then tied back to the main survey network. Each new room was established by resection from the previous room.

Once inside a new room, the network of targets was surveyed. Then an outline of the walls of the room was drawn approximately one meter from the floor using polylines in AutoCAD on a predefined set of layers appropriate for the building type. Features of the room such as: stairs, floor height elevations, changes in grade, appliances, counter tops, nooks, closets, finishes and openings were also measured from the position of the Total Station.

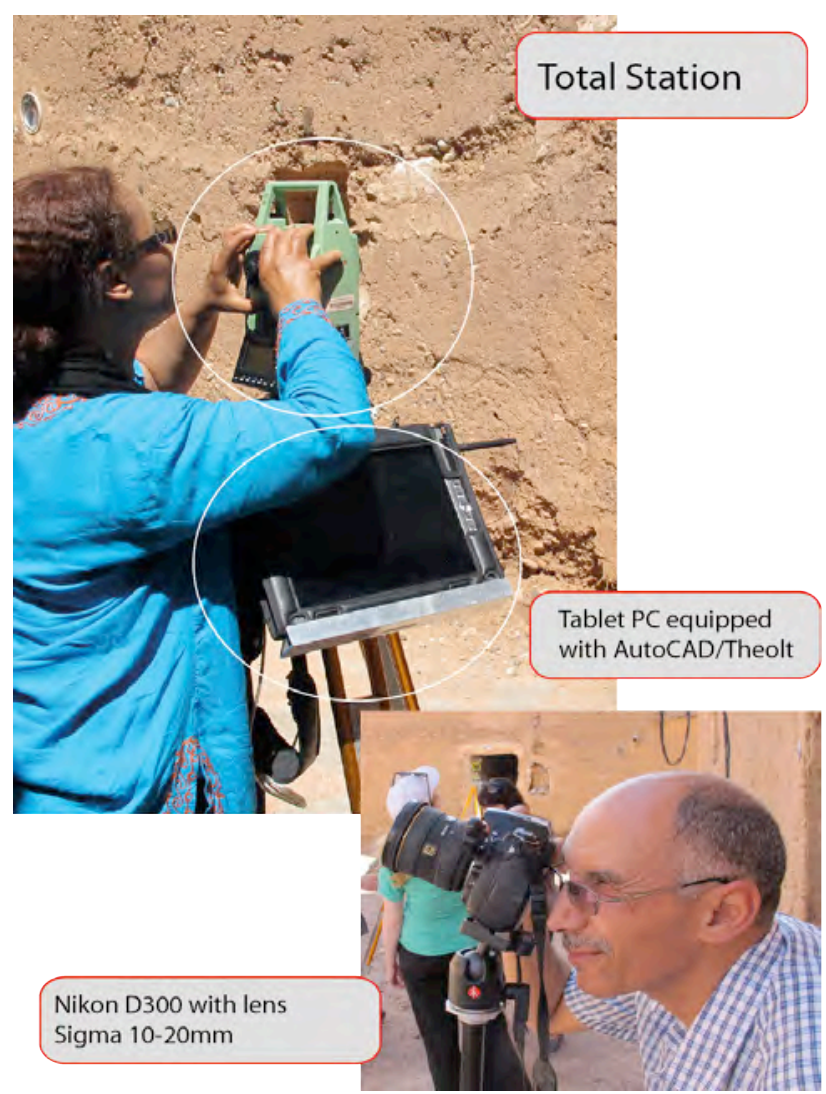

Figure 2: EDM surveying equipment.

One of the big advantages of drawing earth structures directly in AutoCAD from the Total Station was the ability to immediately visualize the collected data. When working with a building lacking traditional orthogonal angles and constantly varying wall thickness, it was found necessary to continually inspect and compare the rooms to the drawing in order to ensure that the extremely complex set of angles and curves were in proper relation to one another. This also proved useful to serve as a communication/planning tool amongst the project team.

\subsection{Georeferencing the Local Coordinate System}

As mentioned in section 2.2, a local system of coordinates was measured, closed, verified and adjusted using closed traverse loops. This system was georeferenced to the Moroccan national grid using a plan of the exterior boundaries of the Kasbah, provided by the municipality, with a list of coordinates indicating the local Moroccan Lambert coordinates.

Additionally, some of the perimeter network points were measured using a GNSS unit equipped with European real-time EGNOS correction to capture other points for georeferencing if required in the future.

\subsection{Digital Photogrammetry}

The second documentation technique utilized was photogrammetry, this tool was chosen to: ensure the documentation team captured all the required information in the time allotted for the field work; and to provide record photography of the captured exterior and interior spaces. This then allowed the documentation team to generate 3D models of the recorded rooms that were then used to extract information needed for the production of the plans, sections and elevations. 
Another advantage to this technique allows the production of other deliverables at a later date, such as sections and plans at different datum's/planes, rectified ceiling plans and orthographic photo elevations.

The exterior elevations were photographed using photogrammetric strips with a $60-80 \%$ overlap. The interior of the rooms typically had a cube configuration (four walls, ceiling and floor). Each interior surface was captured with a minimum of three photos (right, centre and left photo), with oblique photos from each corner of the room. This resulted in about 2230 photos per interior space; which provided sufficient overlap between photos for the bundle registration performed using Agisoft PhotoScan software. The geometry or mesh was then built of all six faces, resulting in a complete 3D model of the space. The same photos used to build the geometry were used to generate a texture. These individual spaces were tied to the project coordinate system, using a minimum of three well distributed targets within the room that were measured with the Total Station.

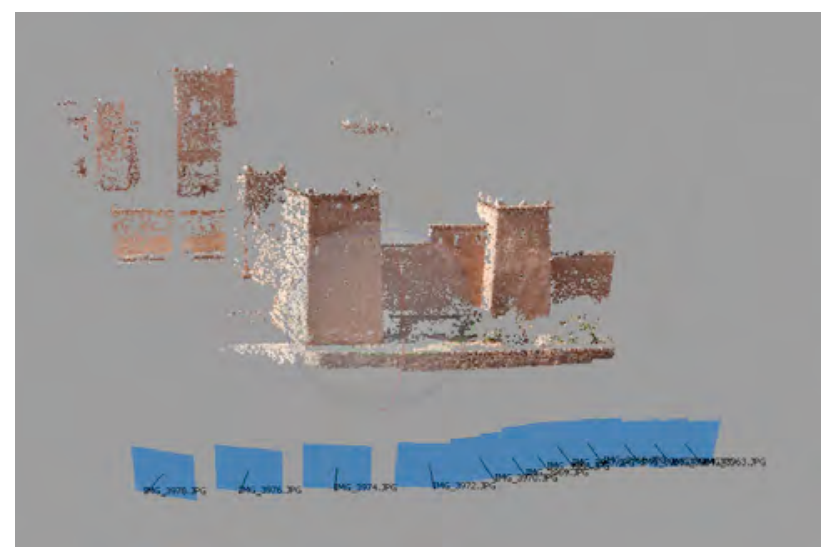

Figure 3: PhotoScan model of the Kasbah, image courtesy of B. Van Genechten.

The photogrammetric models were primarily used to generate horizontal and vertical profiles at pre-determined datum to support the architectural drawings (plans and sections). Orthographic images were also generated, and brought in the architectural plans or sections to infill areas seen in the projection (door and window openings, reflective ceiling plan information, etc.).

\subsection{Panoramic Photography}

A set of several semi and full spherical panoramic photographs were prepared from specified locations throughout the site with the purpose to provide additional graphic information of the site. A Google KMZ file was assembled with the locations of the panoramic images; this file was included in the delivered digital data. Furthermore, an AutoCAD layer at level 1 was also included in the delivered drawings using a photo key plan indicating the location of the prepared images.

The resulting panoramas were prepared by stitching eight overlapping images for a complete coverage of $360^{\circ}$ of the captured scene (six horizontal and two bottom and top views). The images were taken using a Nikon D300 DSLR camera (12.3 megapixel DX format CMOS sensor) equipped with a fisheye Nikkor lens of $10.5 \mathrm{~mm}$ that covers a field of view of approximately $180^{\circ}$ diagonal. To prevent major effects of parallax a Nodal Ninja 3 panoramic adapter was also used.

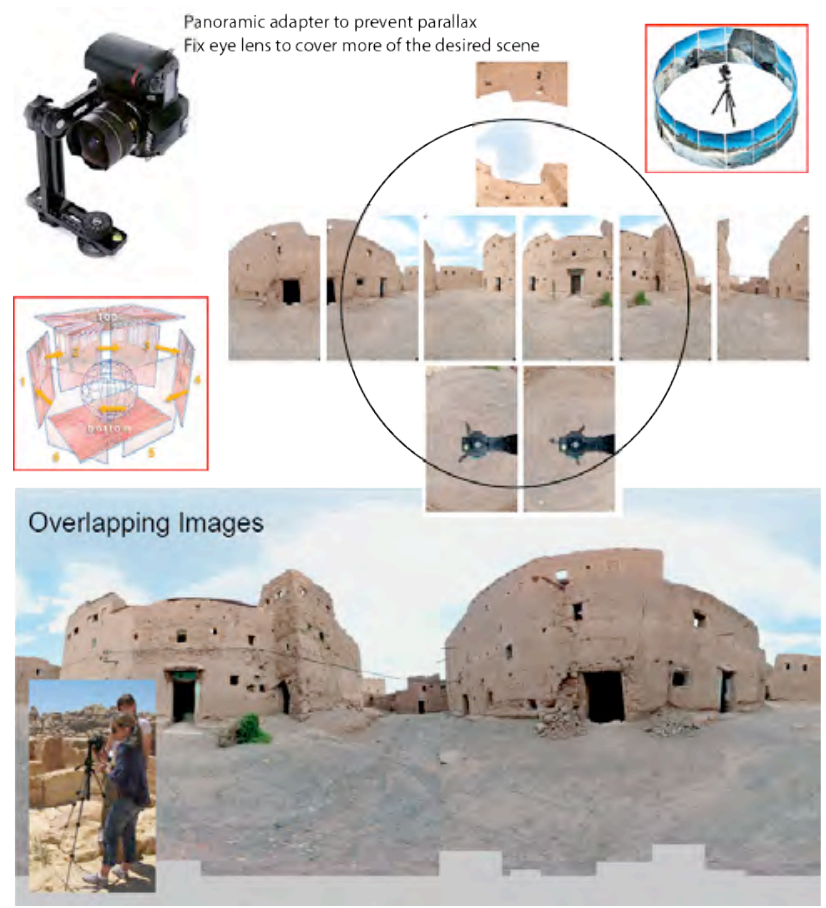

Figure 4: spherical panoramic image.

\subsection{Record Photography}

During the fieldwork, additional record photography was taken from selected areas. These photographs were used to assist with the preparation of the cross section drawings to show the drawing production team additional detail of the areas surveyed.

A photo key plan was prepared to make sure that the exact location and orientation of the photographs was identified. These photographs were used for reference purposes to complement the recording of the Kasbah, when processing the data collected during the fieldwork and produce accurate records of the fabric configuration of the historic place.

\section{PROCESSING}

\subsection{Photogrammetric Models in Geomagic}

During the processing period, the photogrammetric models of most interior and exterior spaces of the complex were imported into Geomagic. These models were used to extract information that was needed for the production of the site atlas.

The created models were cut through at the desired datum/ plane(s). The acquired line drawings from all of the models were then put imported into CAD and combined with the data collected from the Total Station, to complete the site atlas. As each photo and model was linked together via survey points, they got imported into the right location within the CAD drawing. 


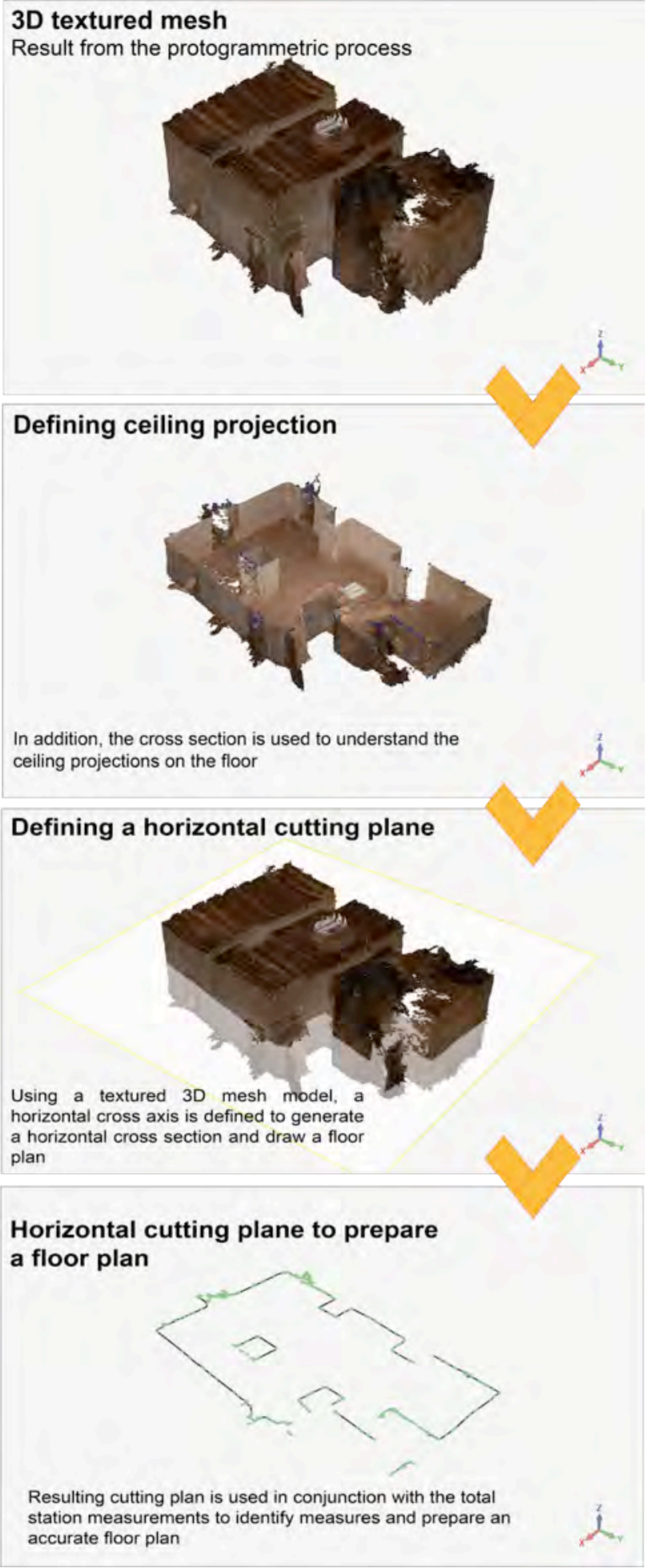

Figure 5: defining a cutting plane to survey the ceiling projections and preparing a floor plan.

Use of photogrammetric models in the documentation of Kasbah of Taourirt allowed for shorter data collection time on site. Since the site was complex and every portion had many different levels, the technology gave the production team flexibility to determine the datum (height) in each individual room, resulting in a higher precision record. This technique also allows for the production of other deliverables in the future such as reflected ceiling plans, photo elevations and sections at different planes that were not part of the original scope of work.

\subsection{Integration in CAD (Plans, Section)}

The final drawing production is an amalgamation of data produced from survey, photogrammetry and hand measurements. Initially, the drawings produced in TheoLt were standardized and refined with hand measurements and photographs. Once these drawings were legible, information from photogrammetric documentation in the form of orthographic photographs and cut lines were integrated. Section lines were geo referenced and as a result, imported in the accurate location. They were then used as a reference to scale imported orthographic photos that were used as a drawing reference.

In situations where the photogrammetric data was the primary source of information, it was also useful to reference the direct survey using the EDM Total Station when determining overall widths and relationships to the other rooms. It is ultimately left to the discretion of the "technician" to interpret the information in the ortho-photographs to gather the required information. In certain instances hand measurements were used along with the Total Station data in the drawing production, mainly to produce sections in rooms where the collection photogrammetric data was not possible. These areas of the sections are visibly different from those that rely on photogrammetric data in that they do not capture the texture and irregularity of the earthen architecture. A higher resolution/higher density of points would have had to have been captured with the Total Station to achieve a similar result as the profiles generated with the photogrammetric model.

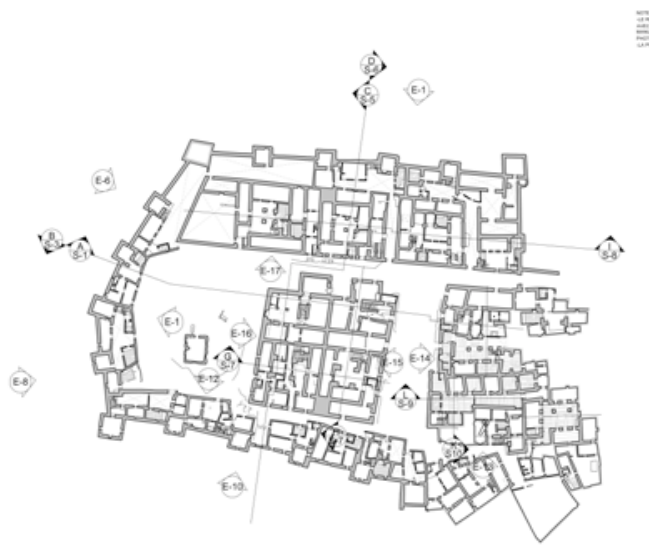

Figure 6: CAD floor plan, with integration of different survey techniques.

The integration of the various documentation methods ultimately produced drawings that captured the data required of the project as well demonstrates the qualities of each method through the aesthetics seen in the drawings. Each method proves to have advantages, either in terms of overall accuracy or depicting the qualitative nature of the structure. The final product validates that Total Station, photogrammetry and hand measurements were effective in producing overall drawings that demonstrate an accurate representation of the site.

\subsection{Creating Reflected Ceiling Plans}

The reflected ceiling plan was requested by the Getty Conservation Institute to understand the physical integrity of the floor/roof in each of the recorded rooms. Given the labour 
intensive work required for measuring these ceilings using the Total Station, the previously generated 3D meshes from the photogrammetric models of the rooms was used. As shown in Figure 4, this approach permitted an orthographic projection of the ceiling to be generated, which was then imported to AutoCAD and overlayed to represent the needed geometry.

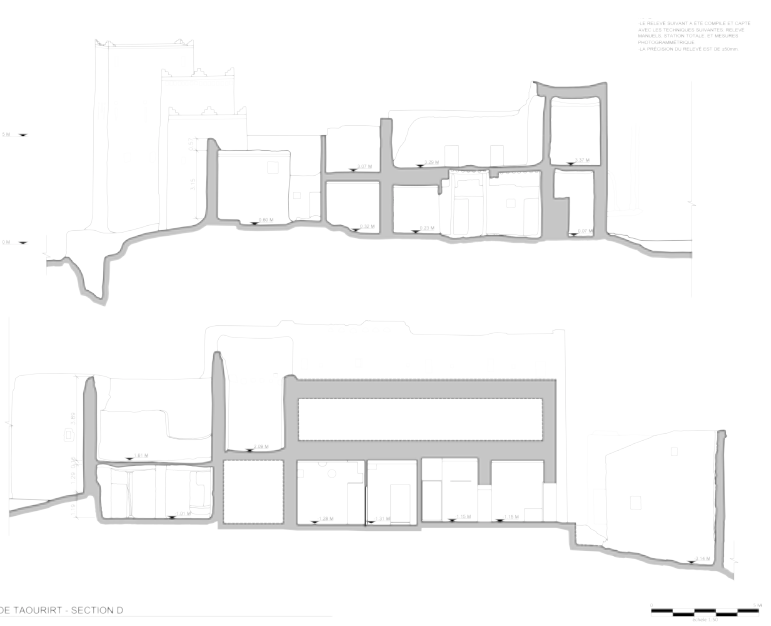

Figure 7: resulting cross section, product of orthographic images using photogrammetry, EDM Total Station survey and overlay using CAD.

\subsection{Use of Ortho Photos for Exterior Facades}

Photos of all the exterior elevations were taken; the photogrammetric rules $(3 \times 3)$ were considered, established by CIPA (ICOMOS CIPA 2013). The photos were taken at an appropriate scale in order to capture the details of the structure, given that the drawing set produced was at 1:50 scale. Due to the verticality of the structure, photos that were taken from the ground were complemented with photos taken from a boom truck provided by the local municipality. This elevated access allowed the team to take pictures of the roof structures as well. During the processing period, the elevations were divided up in order to make the data generation and extraction more manageable. The photos were referenced to the total station data and the project coordinate system using the targets on the elevations captured in the photos.

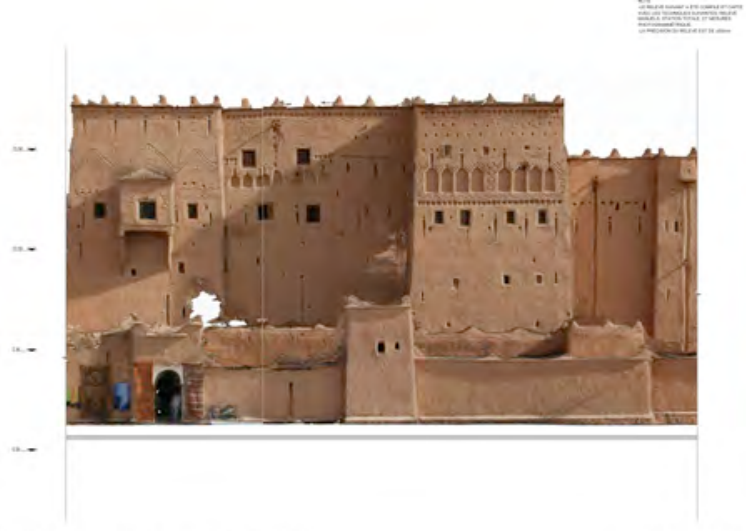

Figure 8: resulting photo elevation with an orthographic image and CAD overlay.

Photogrammetric models were created using the Photoscan software, following the previously explained workflow. Models were then imported into Geomagic, where high quality images of the elevations were printed, and imported into AutoCAD. In $\mathrm{CAD}$, images were traced in order to produce line drawings.

The use of orthophotos allowed the team to produce line drawings for areas that were difficult to access due to the nature of the structure. In addition, with this method, smaller details were captured for posterity and documentation purposes.

\section{TRAINING AND TRANSFER OF KNOWLEDGE}

The project carried out included a "capacity building" component in order to make sure that the approaches used for the recording of this important historic place were transferred to the Moroccan Team in charge of protecting this heritage, as they are the ultimately beneficiaries of this program.

A course was designed with three main components: 1) lectures; 2) field work with demonstrations; and, 3) creation of a Site Atlas (SA). Each lecture provided an overview of metric information needs and recording techniques for the assigned areas within the Kasbah. Although the expected final result was a "site atlas", priority was given to CERKAS team skill development throughout the training activities.

For the completion of the records and supporting lectures, practicum and field work, manuals, tutorials and essential readings were and will be made available, especially recent publications produced by the Getty Conservation Institute on Recording, Documentation and Information Systems for the Conservation of Heritage Places.

The schedule consisted of 16 days of training with an average of 8 hours on surveying techniques for recording historic buildings. The sessions were coordinated by a documentation expert and three specialized experts contributed to supplementary sessions. This course was aimed at providing an approach for the effective use of recording, interpretation (processing), and dissemination in the conservation of built heritage.

The teaching strategy involved an innovative hands-on approach, which empowers participants and instructors to:

- Develop an understanding of the role of information in conservation, addressing national and international standards;

- Review the potential limitations of recording and documentation techniques, including simple and advanced tools, and the financial constraints;

- Develop a practical approach to the use of these tools and documentation techniques in order to capture information from cultural heritage resources;

- Include the use of information systems in cultural heritage resources management; and,

- Design a strategy for presenting information to stakeholders and decision makers.

\section{CONCLUSIONS}

This contribution provides a comprehensive approach that is based on developing "the how" according to the "why" and "when" in heritage recording. The "how" relates to the integration of surveying techniques to capture the geometric configuration of the Kasbah, the "why" relates to the purpose of the records, in this case for conservation and the "when" relates 
to the requirements of the ultimate beneficiaries of this information, the Moroccan partners.

Although there is a vast array of digital techniques of heritage recording that facilitate the capture of historic places quickly and accurately using active (eg. 3D Scanning, Total Stations, etc.) and passive sensors (eg. photogrammetry, rectified photography, etc.), it is important to evaluate what is the required "final " set of deliverables, timeframe available, and the level of expertise available. Heritage documentation projects should not undermine the ultimate goal of producing an accurate diagnosis of the fabric required to extend their life cycle for the benefit of present and future generations.

\section{FURTHER RESEARCH}

Given the team's expertise in 3D modelling and the potential of on-going photogrammetric developments, further research could be conducted in the following areas:

- $\quad 3 \mathrm{D}$ models resulting from photogrammetry and their integration to Building Information Systems (BIM) application to record the current condition of historic earthen architecture places;

- Procedures for actively monitoring historic earthen structures using new advances in photogrammetry;

- $3 \mathrm{D}$ condition assessment using meshes resulting from photogrammetry for historic earthen architecture; and,

- Development of a set of guidelines for rapid assessment and recording of historic earthen architecture structures using low-cost surveying techniques, such as photogrammetry.

\section{ACKNOWLEDGEMENTS}

The authors wish to thank The Getty Conservation Institute (GCI) and the Centre de conservation et réhabilitation du patrimoine architectural des zones atlasiques et sub-atlasiques (CERKAS) for the opportunity to collaborate in this important contribution to science in conserving earthen architecture in Morocco and around the world.

\section{REFERENCES}

\section{References from books:}

CERKAS, UNESCO World Heritage Centre, CRATerre-EAG "Conservation manual: For Earth Architecture Heritage in the pre-Saharan valleys of Morocco" (2005) . pp 220.

Houben, H. Guillaud, H. "Earth Construction" ITDG, CRATerre-EAG, France. Pp. 123.

ICOMOS UK 'Guidelines to Recording Historic Buildings' (1996). Pp. 120-122.

Patias, P. Santana Quintero, M. Introduction to Heritage Documentation, In CIPA Heritage Documentation best practices and applications, Stylianidis, E. Patias, P. Santana Quintero, M. ed. The ICOMOS \& ISPRS Committee for Documentation of Cultural Heritage. The ISPRS International Archives of the Photogrammetry, Remote Sensing and Spatial Information Sciences, Vol. XXXVIII-5/C19. ISSN 1682-1750. Pp 20-30.
Terrase, H. Kasbas Berberes: de l'Atlas et des oasis: Les grandes architectures du Sud marocain (2010) $2^{\text {nd }}$ edition, Actes Sud, Centre Jacques-Berque. Pp. 213-215.

\section{References from websites:}

Agisoft. Product description http://www.agisoft.ru/products (24 Jun. 2013) Agisoft. Photoscan $\quad$ pro
http://www.agisoft.ru/tutorials/photoscan (24 Jun. 2013)

English Heritage 'The Presentation of Historic Buildings survey in CAD' (2005), Swindon, UK. http://www.helm.org.uk/guidance-library/historic-buildingsurvey-in-cad/ (24 Jun. 2013)

Eppich, E. Chabbi, A. ed. 'Illustrated Examples Recording, Documentation, and Information Management for the Conservation of Heritage Places' The Getty Conservation Institute, J. Paul Getty Trust (2007), retrieved from: http://www.getty.edu/conservation/publications resources/pdf publications/recordim vol2.html (24 Jun. 2013)

Geomagic, Geomagic Studio Overview http://www.geomagic.com/en/products/studio/overview Jun. 2013)

The Getty Conservation Institute Facebook page https://www.facebook.com/media/set/?set=a.444655202271823. $102710.294993627237982 \&$ type $=3$ (24 Jun. 2013)

Letellier, R. Schmid, W. LeBlanc, F. 'Guiding Principles Recording, Documentation, and Information Management for the Conservation of Heritage Places' The Getty Conservation Institute, J. Paul Getty Trust (2007), http://www.getty.edu/conservation/publications resources/pdf publications/recordim.html (24 Jun. 2013)

Lardinois, S. Getty Conservation Institute- Getty Iris. "A Project of Seismis Proportions" (2011) http://blogs.getty.edu/iris/a-project-of-seismic-proportions/. (24 Jun. 2013)

Lardinois, S. Getty Conservation Institute- Getty Iris. "A Project of Seismis Proportions" (2011) http://blogs.getty.edu/iris/a-project-of-seismic-proportions/. (24 Jun. 2013)

Latimer CAD "TheoLt 8.22 User Guide" (2012), http://www.theolt.com/web/theolt-support/ (24 Jun. 2013)

Tolles, E.L. et.al. "Seismic Stabilization of Historic Adobe Structures" The Getty Conservation Institute, J.Paul Getty Trust (2000)

http://www.getty.edu/conservation/publications_resources/pdf_ publications/pdf/seismicstabilization.pdf (24 Jun. 2013)

UNESCO World Heritage Centre - World Heritage Earthen Architecture Programme (WHEAP)." UNESCO World Heritage Centre. (2007) http://whc.unesco.org/en/earthen-architecture/ (24 Jun. 2013) 